\title{
Building Community in Online Professional Practice Doctoral Programs
}

\author{
Cece Lynn Lively \\ Baylor University \\ cece_lively@baylor.edu \\ Brooke Blevins \\ Baylor University \\ brooke_blevins@baylor.edu \\ Sandra Talbert (D) \\ Baylor University \\ sandra_talbert@baylor.edu \\ Sandi Cooper \\ Baylor University \\ sandra_cooper@baylor.edu
}

\begin{abstract}
Despite high attrition rates and abundant criticisms, online graduate programs continue to grow. This paper describes the efforts of one online doctoral program that focused on developing programmatic support structures to increase community. Utilizing a qualitative, case study research design, including surveys and semi structured interviews, this study examined two research questions: a) In what ways did students experience a sense of community? b) What elements of an online professional doctoral program did students find most influential in developing a learning community? Findings indicate that students experience community through peer collaboration, program support, and shared learning and networking. A sense of community was developed through the cohort model, strong student support services, synchronous live sessions, and relationships formed with faculty. As a result, a community of practice was formed among program participants. Findings from this study have the potential to aid other online graduate programs as they design and implement structures to foster student success and retention.
\end{abstract}

\section{KEYWORDS}

community, online education, EdD, cohort, student support

\section{INTRODUCTION}

According to a recent report citing enrollment in graduate programs, online graduate programs dominated the virtual program landscape in 2019 (Schaffhauser, 2020). Due to rising numbers of programs offering online degree options, it is imperative for practitioners and scholars to examine the needs of students in virtual classroom environments that foster success at all levels as they matriculate and grow as scholars. Historically, online education has been criticized for its lack of human connection in coursework in the broader field of education. Traditionally, online programs have been viewed as void of meaningful interaction with asynchronous message boards and impersonal, irregular feedback. In addition, studies have identified shortcomings among online programs such as a lack of connection as well as feelings of isolation (Bettinger \& Loeb, 2017). Researchers have found that students in distance learning programs may be more likely to experience isolation and Commons Attribution 4.0 United States License. alienation from the institution because of their physical separation from the school and its services and from other students (Rovai \& Wighting, 2005, p. 97).

Despite these concerns, online graduate programs continue to grow (Schaffhauser, 2020). As such, it is critical to recognize the importance of building a community among these virtual learners and then act on ways to incorporate strategies to help develop a tight-knit community, regardless of the students physical proximity to each other or the brick and mortar campus. In this article, we investigate the outcomes of one online doctoral program that focused specifically on building high quality learning communities to transcend criticisms related to poor human connection and disjointed approaches to online education. Using innovative learning environments and community building practices alongside engaging 
instructional models and student support services, our program worked to create meaningful connections with and among students.

\section{FRAMING THE ISSUE}

Several studies have identified empirical evidence of educational shortcomings among online programs, including lack of faculty student connection, isolation and alienation (Rovai \& Wighting, 2005), low academic performance (Bettinger \& Loeb, 2017), and lower retention rates (Rovai, 2003). Many of these shortcomings may contribute to the disheartening $50-70 \%$ attrition rates within EdD programs (Ivankova \& Stick, 2007; RockinsonSzapkiw et al., 2014). To overcome these shortcomings and reduce attrition, attention must be given to building community and increasing connections among online doctoral students. Regular and genuine student-to-faculty and student-to-student interaction produces quality online education, which leads to increased student outcomes (Endo et al., 1982).

When students feel connected to a community, stronger classroom interactions and discussions often occur. That feeling of connectedness helps retain learners and create community investment. The connections that can occur in a community of practice are incredibly important when considering the implementation of online courses. In a 2008 survey of 3800 students taking online courses through State University of New York's online network, Swan et al. (2000) discovered that the more interaction students had with their instructor and fellow peers, the more they thought they learned and the more satisfied they were with their courses. Social presence in live face-to-face online courses is an exceptionally effective way to create a learning community. Rourke et al. (1999) defined social presence as 'the ability of learners to project themselves socially and effectively into a community of inquiry' (p. 50). Creating a connection to the rich asynchronous coursework, providing a face-to-face live online class session for discussion, and offering an opportunity for students to serve as a community of learners can work together to create an ideal learning environment for professional practice doctoral students to learn online.

The theory of doctoral student persistence suggests the primary communities for students relative to their graduate education are their peers and the faculty in their programs (Tinto, 2010). The cohort model is one potential way to enhance the learning community (Browne-Ferrigno \& Maughan, 2016), bringing students together with their peers. Because students in a cohort are on a set course sequence together, they are able to encourage, uplift and interact with one another offering psychological support, stronger affiliation with other members, and an overall reduction in loneliness (Hill, 1995). With a common purpose and a common goal, students involved in these cohort models are often in a better position to form communities of practice that lead to greater student persistence and success (Norris \& Barnett, 1994; Bagaka's et al., 2002). The role of the doctoral mentor or doctoral advisor weighs heavily in the doctoral student success and persistence. Research suggests that hands-on mentorship in the form of a faculty advisor is required to support doctoral students (Lovitts, 2001).

The research literature draws attention to the need to develop communities of practice in order to foster meaningful online education. Communities of practice are formed by people who share a common concern for what they do, and generally make each other better as they learn together (Lave \& Wenger, 2002; Wenger, 1998). Investing in a community of practice can aid in students' overall academic progress. As such, our online EdD program adopted a community of practice model that consists of students, faculty, and staff who interact on a regular basis through coursework, student support services, immersion activities, and faculty-student advising models.

\section{DESCRIPTION OF THE PROGRAM}

Based on the research literature, we intentionally designed our online program to have high quality interaction with and among our students. Researchers have suggested several potential support structures for EdD students including, peer mentoring (Lowery et al., 2018), cohort models and community building (Bista \& Cox, 2014), library support (Tuñón \& Ramirez, 2010), and focusing on practice based and authentic research (Kerrigan \& Hayes, 2016; RockinsonSzapkiw et al., 2014). The recruitment and retention of students through innovative and rigorous academic and professional development preparation is buoyed by our program vision and faculty mission to engage all learners in a community of reciprocal mentoring and accountability. Although we have high expectations for all of our students, we work to provide support for them throughout their journey towards degree attainment - both academic support and social/emotional support to help them feel they are a part of our greater university community.

Our EdD Online program is designed as a three-year program, with a specific course sequence organized in 14-week trimesters. Students enter as a cohort and take two courses per trimester. They are required to complete a Problem of Practice (PoP) dissertation, but this work is organized into a series of four PoP courses taken over the three year program. EdD students are assigned a primary Faculty Advisor who serves as the instructor for their PoP courses and guides the entire development of the PoP. Below we describe several key programmatic elements designed to help reduce transactional distance (Moore, 1993), cultivate community (Tinto, 2003), build relationships (Gisemba Bagaka, et al., 2015), and create a sense of belonging (Curtin et al., 2013).

\section{Cohort Model}

Our program utilizes a cohort model in which students progress through their educational experience together. With a cohort size of about 45-65 students, each cohort follows a specific sequence of classes each trimester and engages in the problem of practice dissertation process at the same time. Research results have long supported the cohort model as an effective practice to increase collaboration, encourage shared learning, cultivate teamwork and innovation, build support networks, and sustain students towards completion of their doctorate degree (Lange, Pillay, \& Chikoko, 2011).

\section{Immersion Experiences}

Immersion experiences are designed to bring students physically together on campus at two specific times during their entire EdD program. During the first immersion experience, students participate in a two-day workshop where they begin to work on elements of their Problem of Practice (PoP) with the assistance of EdD faculty and staff. During the second immersion experience, 
students return to campus to engage in peer working group sessions and present their PoP dissertation in a poster format. Immersion experiences not only give students the opportunity to meet their classmates in person but also offers hands-on learning that will empower graduates to enter the field with confidence. The series of immersion experiences cultivates community, is invaluable to the EdD online program, and imperative to formulating the PoP dissertation.

\section{Student Support}

Student Support is generally a model reserved for undergraduate students. However, we recognized the importance of having systems in place to support students across the program. Upon admission, each student is paired with a dedicated student success advisor (SSA). The Student Success Advisors (SSAs) work closely with students on many issues, including technology, systems support, program information, as well as general goal achievement coaching. The SSA conducts regular phone call check-ins, assists with degree plans, and serves as a sounding board for all things EdD and course-related.

In addition, the program supports its own writing center for student use. The EdD Writing Center provides writing support to the Online EdD students through all stages of the writing process. Regular writing workshops and individualized writing consultations are conducted via Zoom on an appointment basis. The EdD Writing Center specializes in writing development strategies, meaning that rather than proofreading documents, the focus is on identifying key writing techniques and practices that can help students grow as writers beyond the individual documents that are reviewed.

\section{Live Sessions}

In addition to the 90-minute weekly asynchronous sessions, students also attend a 90-minute synchronous, or live, session of class each week of the trimester. During this time, the professors actively engage students in extension of material covered in asynchronous work, introduce new and supporting information on the topic, and provide students opportunities to apply what they have learned. The live sessions generally consist of whole group discussions and breakout rooms where students are asked to complete various activities with small groups of their classmates. Additionally, during live sessions, students often engage in group as well as individual presentations. Although the goal of live sessions is to elaborate and extend the material, an important component is the community that is fostered through the sharing of ideas, views, and experiences. Students learn about their classmates' professional roles as well as their personal experiences. Not only do the students build a network of colleagues, but they also build a network of friends (McMillan et. al, 1986).

\section{Faculty Advisors}

Faculty advisors serve their assigned group of cohort students as instructor, mentor, guide, and overall supporter. The role of the faculty advisor is essential in building community among the students. During their first Problem of Practice dissertation course (Trimester 5), students often struggle and are overwhelmed with the daunting task of completing Chapters 1 and 2 in one trimester. However, we have found that having one key contact person - the faculty advisor - gives students a sense of security and encouragement that someone is going to be there with them every step of the way. Faculty advisors develop relationships with their students; they become intimately acquainted with the students' research topics; they know the students' strengths and weaknesses, and, generally, they get to know the students on a personal level. Students often reach out to their faculty advisors, even during the trimesters in between the assigned Problem of Practice courses. Students regularly note the support, encouragement, and guidance that they receive from their faculty advisor as one of the highlights of the program.

\section{Peer Working Groups}

While in their faculty advisor groups, students are assigned to smaller groups of 3-4 students called Peer Working Groups. Peer working groups are generally assigned based on shared topics of interest and/or topics of their Problem of Practice studies. Peer Working Groups meet weekly to collaborate, provide feedback on each other's thinking and writing, answer questions and share resources, and generally encourage one another during the Problem of Practice dissertation phase. Through peer working groups students engage in both self-reflection and peer dialogue.

Taken together these program components have been instrumental in supporting students throughout the program. Notably, based on program data, the current attrition rate for our program is only $17 \%$, with most of those students exiting within the first three trimesters. Information gathered in exit interviews revealed the reasons behind student withdrawals at this stage are attributed to personal needs, family needs, or financial concerns.

\section{METHODOLOGY}

To examine if and how the Online EdD program cultivated community as a result of our purposeful efforts, this study centered around the following research questions:

1. In what ways did students experience a sense of community?

2. What elements of an online professional doctoral program did students find most influential in developing a learning community?

To answer these questions, this study utilized a qualitative research design (Merriam, 2008; Stake, 2006). Data were collected from students in our first four doctoral cohorts. Three primary data sources were used to inform our study including student surveys $(n=248)$ and semi-structured and open-ended interviews $(n=89)$ (Creswell, 2002; Merriam, 2008; Stake, 2006). The survey was administered electronically at the end of each trimester and included open-ended questions asking students to describe their experience in the program including interactions with faculty, students, and student support services. Interview protocols consisted of brief, semistructured interviews with 89 students representing each of the four cohorts. Interviews were manually transcribed and coded for emerging themes. Interview themes were then compared with themes that emerged through student surveys. Thematic analysis was utilized to analyze student feedback data, noting similarities, differences, categories, concepts, and ideas to ensure that participant voices and ideas led to the emerging patterns and themes (Strauss \& Corbin, 1990). Throughout the process, we referenced the other data sources as a means of triangulation. This led to the results discussed below. 


\section{RESULTS}

Data analysis revealed several important themes related to the research questions. In the following section, we describe the results from our data analysis in relation to the two research questions.

\section{RQ \#1: In what ways did students experience a sense of community?}

For the first research question, data analysis revealed that students experience community through peer collaboration, program support, and shared learning and networking. Below we describe each of these experiences in more detail.

\section{Peer Collaboration}

In describing peer collaboration, students cited the collaborative nature of the classes. For instance, one student remarked:

The cohort model gives students a true opportunity to collaborate and build community with intelligent and driven professionals in their field. This collaboration is leading to life-long friendships. Since my peers come from a variety of backgrounds and professions, what I love most is that I am learning so much from my peers in professional fields other than mine!" (Written response, end of term survey respondent \#15).

Another student shared about the diversity of ideas experienced in live class sessions with their classmates by saying, "..it has been an awesome experience connecting and collaborating with so many people from different backgrounds" (Interview response, interview participant \#24).

Students often remarked about the connections made with colleagues in other professions all over the world. They identified the ability to create new and meaningful relationships as key to the sense of community and success they experience. One student remarked, "Since my journey began, I have felt more connected with my colleagues and professors, through collaboration and enriching discussions, than I ever thought possible from a distance learning environment" (Interview response, interview participant \#12). Another student shared that, "The strength of the program resides not only in the material that is presented, but the truly collaborative cohort of professionals that explore, encourage, critique, and support one another" (Interview response, interview participant \#50).

In addition to peer collaboration as a means of experiencing community, the students noted that program support was also essential in their success and sense of belonging.

\section{Program Support}

Students consistently remarked about the high level of support they experienced in the program. When describing programmatic support structures, one student shared, "The support the EdD program provides through the student success team, writing center advisors, and accessible faculty members has been the most welcome surprise during my first trimester" (Interview response, interview participant \#46). In addition to program structures, student connections with their colleagues led to an overwhelming sense of genuine care and community within the program with another student remarking:
Perhaps the best part of it [the program] is the learning community that has developed. My classmates and I communicate constantly and have developed a nice support structure for each other; this also widens my professional network, which I think is an under-appreciated feature of the program. (Written response, end of term survey respondent \#114)

In addition, a caring and supportive faculty with positive interactions ranked high for students. For instance, one student wrote:

I love that my instructors and classmates became invested in me as a person. I'm not just a name on a roster. Two weeks into the trimester, I was in a pretty serious car accident. My car was totaled, and I was out of work. I told my instructors and classmates, and they were extremely accommodating. My classmates emailed to check on me when they found out. I think this made us less like classmates and more like family. I guess that means I mostly like the camaraderie of the program. (Written response, end of term survey respondent \#11)

Genuine care and community within the program from the faculty and staff is a sentiment felt at the student level with remarks such as, "I have never felt so much support from the faculty and staff since I started my journey. Their support has been something I have truly cherished" (Interview response, interview participant \#54).

\section{Shared Learning and Networking}

Through their interactions with peers from diverse personal and professional backgrounds, students had the opportunity to engage in shared learning and networking, which fostered the development of community. One student remarked, "I'm a better friend, employee, and advocate every day that I spend in this program. The work we are doing elevates my capabilities and character in a way that no education in my life has done before" (Interview response, interview participant \#65). Students seemed to place great value in these shared experiences with comments like:

The EdD online platform offers professionals the opportunity to continue their educational journey in a collegial environment. My cohort is amazing, and I appreciate the shared wealth of knowledge from each person and thankful I am taking this journey with them! (Interview response, interview participant \#8)

In the live sessions, students are also able to learn from one another in class discussions and breakout rooms. One student reflection noted:

The EdD program is a perfect fit - the courses challenge me as a student and support me as a professional. While I look forward to the live lectures each week, my favorite part of class is the breakout room, where I get a chance to learn directly from my peers. (Interview response, interview participant \#16)

Another shared, "My favorite aspect has been the classroom discussions we have had throughout the trimester. It has been an amazing experience to hear the different perspectives that each student provides in the classroom" (Interview response, interview participant \#14). Recognizing that these learning experiences allow for a closeness with fellow classmates that would be difficult to replicate in a traditional classroom, one student shared: 
The program provides me the unique experience of taking classes and coursework with individuals across the country that approach their work uniquely. These experiences would have been difficult to attain in one centralized classroom. My peers, professors, and advisors transform my approach to everyday issues with deep and riveting discourses and their experiences shape my approach to every individual. (Interview response, interview participant \#26)

The relationships developed by networking through these shared learning experiences played an integral role in developing community among students.

\section{RQ \#2: What elements of an online professional doctoral program did students find most influential in developing a learning community?}

For the second research question, data analysis revealed four primary programmatic elements that helped develop a sense of community, including the cohort model, strong student support services, synchronous live sessions with collaborative learning, and rich advisor/student relationships formed through working on the Problem of Practice dissertation. Below we provide examples of student data that highlight programmatic elements that helped to foster a rich learning community.

\section{Cohort Model}

The previously described cohort model resulted in increased feelings of community among the students. Students developed both professional as well as personal relationships with the other students in the cohort. Interview and survey responses showed that students developed these relationships through shared experiences, common goals, and a united sense of purpose. Over $50 \%$ of the students interviewed made some mention of the impact of the cohort model on their experience in the program. When describing the cohort model, students shared feelings of respect, admiration, and powerful learning experiences. For instance, one student remarked: "I have such respect for my cohort and the diversity of demographics and experiences that are brought to our learning" (Written response, end of term survey respondent \#20). Another noted, "I am really enjoying getting to know my cohort classmates, especially those who do not have the same professional background that I have. This diversity makes our conversations rich" (Written response, end of term survey respondent \#111). These quotes showcase the important role that the cohort model played in cultivating relationships across differences, including cultural and professional diversity. Remarking on the impact of these relationships, one student commented, "I love working with my cohort in small group discussions and finding out about the diversity of experiences in the Education field. It makes the material more meaningful and applicable to the professional world" (Interview response, interview participant \#87). The cultivation of relationships through the cohort model helped students to develop relationships that were meaningful both personally and professionally. One student wrote, "I have gained friends in this degree program. I am actually going this weekend to meet another cohort member in person for the first time!" (Written response, end of term survey respondent \#70). Students often remarked about how the cohort model allowed them to learn from and alongside others, including one who said, "The most meaningful and impactful experience has been getting the opportunity to learn with and from the others associated with the program." (Interview response, interview participant \#19). The cohort model was a powerful programmatic element that cultivated a sense of community among students.

\section{Student Support Services}

Participants overwhelmingly identified student support services as an important programmatic support structure that helped to cultivate community. Students have access to student success advisors, a designated EdD writing center, assigned faculty advisors, and open access to the director and assistant director of the EdD program. One student noted, "The program has provided a lot of support for students, more than I have received at any other university. I appreciate the guidance and help especially returning to school after a long hiatus." (Written response, end of term survey respondent \#163). Another remarked, "I love all the resources that are available to us. The program goes the extra mile with providing so many areas to help us succeed. For example, writing center, tutors, office hours with professors, etc." (Written response, end of term survey respondent \#57). When describing the student services available to them, students shared feelings of support and encouragement and described the experience as valuable. Comments included, "So far it has been rigorous, but I have access to the supports I need to be successful," (Written response, end of term survey respondent \#149) and "I feel supported: My success is University's [pseudonym] success." (Written response, end of term survey respondent \#37), "The support University is giving is SUPERIOR!" (Written response, end of term survey respondent \#170), and "I feel supported to be successful!" Written response, end of term survey respondent \#93).

Many students pointed out the important role of their student success coach. One student commented, "I love EVERYTHING about the success team! Having a success coach is a wonderful concept and tremendous help as I navigate through such unfamiliar territory." (Written response, interview respondent \#79). Another remarked, "I like the calls from Student Success as they helped me navigate potential hot spots without feeling like I had to find someone to contact. (Written response, end of term survey respondent \#158). One other said, "The positive and motivational demeanor of our student success coach was influential in my completion of the trimester." (Written response, end of term survey respondent \#17). Participants also highlighted the support they found in the EdD Writing Center, "I think the program is very engaging and is providing me with the skills and tools necessary to achieve my educational and professional goals. The EdD Writing Center was also extremely helpful! The input and help from the Writing Center Staff helped me complete my coursework with excellence." (Written response, end of term survey respondent \#171). These data showcase the role that student support services played in students' sense of connection within a learning community.

\section{Synchronous Live Sessions}

The live class sessions were another programmatic element that many participants referred to as important in developing a shared learning community. When describing their experience with live class sessions, students expressed feelings of connectedness, interaction, and deep personal and intellectual growth. In regard to feeling connected through the live session, student comments included, "I particularly like the live sessions because it feels like an actual classroom and I'm making connections with other people 
(networking!)," (Written response, end of term survey respondent \#150); "I appreciate the live sessions which enables you to feel like you're in a brick and mortar situation and it also allows you to connect to fellow classmates." (Written response, end of term survey respondent \#266), and "The live sessions have been awesome and I feel like I'm really attending class on site. I am honored to be a part of the University family! I feel welcomed and like a member of the community." (Written response, end of term survey respondent \#93).

Participants also noted how the live sessions promoted intellectual growth and academic rigor. One student remarked, "I love the live class sessions and interacting with my talented classmates.... I have learned not only from the program curriculum but from my classmates as well; what an added bonus! (Written response, end of term survey respondent \#110). Another student noted, "I love the live class meetings over Zoom and getting to see the faces of my classmates. I love the break-out sessions and the group work. I love that I am being made to think harder than I have in a long time so I can grow as a person." (Written response, end of term survey respondent \#6). Several additional comments highlighted how the live sessions were a distinguishing feature of the program and differed from other online learning programs students had experienced.

I enjoy interacting with faculty and the other members of our cohort during the synchronous sessions. Whether we are spending time in breakout rooms with a few people or with the larger group, the time goes by quickly. I previously attended another program that was $100 \%$ asynchronous work was mundane. (Interview response, interview respondent \#75)

I've been really amazed at just how well the faculty make use of the face-to-face sessions. They're very interactive and capitalize on bringing in the diverse set of perspectives in the class. This is the first time l've experienced an online degree program that really felt like it was optimized for remote learners. (Interview response, respondent \#39)

Data analysis revealed that the live synchronous sessions were instrumental in developing a learning community among students.

\section{Program Faculty}

Over $80 \%$ of student responses noted the importance of program faculty in their sense of purpose and community. The relationships developed between the faculty and the students were key to developing a learning community among our students. When describing the relationship between the student and the faculty member, students expressed a sense of confidence, dedication, and an overall feeling of support from the faculty member. One student noted:

The EdD program has holistically inspired my curiosity, challenged my intellectual and analytical capacities, and authentically cultivated my academic potential. The professors are eager to foster your development, and classrooms are filled with fervent individuals from diverse cultural and professional backgrounds. Thus, this scholarly research community is vibrant, pragmatic, and purposeful as well as accepting of perspectives outside the education sector. (Interview response, interview participant \#58)
Students overwhelmingly remarked about faculty members' knowledge, expertise, and passion. Student comments included, "The University has professors that are knowledgeable and tenured enough within their area of expertise to use that as a benefit." (Interview response, interview participant \#24), " There is so much passion from the faculty. I appreciate the interest and the support and motivation from most of the faculty. I appreciate that they are letting us voice our opinions on things," (Written response, end of term survey respondent \#77), and "I appreciate the passionate, astute, and supportive instructors!" (Written response, end of term survey respondent \#80)

Data analysis also highlighted the role faculty played in encouraging and supporting students. One student wrote, "The professors I have are incredible and contribute to my confidence in the quality of the program. The program has been well-planned and organized." (Written response, end of term survey respondent \#28). Another noted, "The overall program is so supportive with the student success team as well as amazing professors who are so flexible and understanding of how life happens." (Interview response, respondent \#13). Other students commented, "The personalized attention you receive as a Baylor Bear is next level! I have been impressed with how committed the faculty is to student success. This has been a constant theme from day 1" (Interview response, respondent \#79), "The faculty are amazing and very helpful. They truly want us to learn and understand. They are also approachable which is the best thing about the program!" (Written response, end of term survey respondent \#49), and "the faculty/staff has been very attentive and supportive of me (often unprompted) throughout the trimester." (Written response, end of term survey respondent \#34). Program faculty's expertise and supportive dispositions played a key role in cultivating a shared learning community among students.

\section{DISCUSSION}

Our results highlight the ways in which students experience involvement in a learning community and how this learning community enhances student learning and persistence (Cross, 1998; Tinto, 2003). In answering our two research questions, we discovered the ways in which students experience community, through peer collaboration, program support, and shared learning and networking, intersected with the program supports that they identified as most helpful including the cohort model (Lange, Pillay, \& Chikoko, 2011) strong student support services (Reynolds \& Hebert 1998), synchronous live sessions with collaborative learning (Gardner, 2008; Tu \& Corry, 2003), and strong faculty student relationships (Gisemba Bagaka, et al., 2015). This type of support has been found to relate positively to the level of motivation to persist (Wentzel, 1999; Eggens et al., 2008).

The collaboration that results in a sense of community in the EdD program is not happenstance; instead, it was intentionally planned and cultivated in a variety of ways by program faculty and staff. Recognizing low persistence rates among doctoral programs nationwide (Golde, 2005; Terrell, 2005; Terrell et al., 2012), the support systems offered to our students are purposefully designed to increase student persistence. We knew early on that students in this accelerated program would include full-time working professionals, many with families and demanding community responsibilities. In developing the support structures over time, faculty and program leadership noticed an increased opportunity to support and encourage our students. Through the process of helping our 
students feel supported, a sense of community has emerged. Consequently, the program has helped to cultivate a community of practice defined by three essential elements: "a domain of knowledge, which defines a set of issues; a community of people who care about this domain; and the shared practice that they are developing to be effective in their domain" (Wenger, et al., 2002, p. 27, emphasis in the original). As Browne-Ferrigno and Maughan (2016) noted, "engaging actively in a CoP can expand participants' opportunities for professional growth and career advancement through sharing of expert knowledge and development of collegial relationships." (p. 49) The students have developed these collegial relationships and created networks of professionals as evidenced through their comments in interviews and survey responses. These connections are a cornerstone of the students' rich experiences.

Recognizing the lack of connection in asynchronous only online programs (Rovai \& Wighting, 2005), a critical choice was made to include face-to-face synchronous class times in addition to asynchronous course content. While that decision meant dedicating a time and day each week for class sessions, the synchronous experience has proven crucial in the development of a community of practice. In that shared learning time, students engage in deep and meaningful interactions with their peers and professors that has helped to build a stronger tie to the program and to the overall community of learners. Most of our faculty had not previously taught online and were rather concerned about how they would transfer their learner centered instructional practices, such as discussion, student presentations, and collaboration, into an online format. Thus, when planning the asynchronous as well as the synchronous material, the faculty worked together to purposefully incorporate opportunities for students to work together in a multitude of ways such as whole class and small group discussions, student led presentations, collaborative projects, and peer-working groups. The development of high quality asynchronous and synchronous material allowed students to develop a domain of knowledge that cultivated a common understanding and shared sense of identity as a cohort. This domain of knowledge "inspires members to contribute and participate, guides their learning, and gives meaning to their actions." (Wenger et al., 2002, p. 28)

Developing a dynamic interface, involving thoughtful and highquality instruction, and working toward discussion-based learning are keys to achieving this successful synchronous learning experience (Swan et al., 2000). The second element of a community of practice was cultivated in large part during the time students spent in synchronous class sessions where they interacted as a whole group as well as in smaller breakout groups. As Wenger et al. (2002) noted, "The community creates the social fabric of learning. A strong community fosters interactions based on mutual respect and trust. It encourages the willingness to share ideas, expose one's ignorance, ask difficult questions, and listen carefully." (p. 29) Students consistently noted that many of their relationships were built and strengthened through the time in the live sessions. During live sessions, including small group breakout rooms, students had the opportunity to share ideas, explore various perspectives, ask questions, and learn from others. Rather than simply completing online work individually, live sessions created the space for students to develop relationships of respect and trust with their colleagues and faculty.

The cohort model also allowed students to develop relationships with their classmates which resulted in support, encouragement, camaraderie, and diversity of thoughts and ideas.
Student comments highlighted the ways in which the cohort model helped to create a community of learners. Students developed both personal and professional relationships with cohort colleagues as they took classes together and worked on the Problem of Practice Dissertation in tandem throughout the program. As the closed-cohort progressed at the same pace through the curriculum, they had ongoing opportunities to interact with one another, share experiences, and work toward a common purpose which contributed to the development of a community of learners and practice (Maher, 2005; Wenger et al., 2002). Additionally, the immersion activities provided multiple opportunities for students to interact with members of their cohort in multiple settings. Participant comments illustrate how powerful collaboration and ongoing peer support was in creating deeper interpersonal ties and shared experiences (Maher, 2005). Through the cohort model, students received the benefits of a built-in support system of peers, social support, a personal network, and powerful peer learning. Wenger et al. (2002) noted that "community is an important element because learning is a matter of belonging as well an intellectual process, involving the heart as well as the head" (p. 29). The multitude of community-building opportunities through the cohort model add a richness to the students' experiences, cultivate peer mentorship, and allow students to make connections that will last beyond the completion of their degrees.

Another key theme that emerged from student data was the importance of the support services provided by the program. Student support services that work to foster growth and development in the whole student experience, not just academic in nature, are another key element in fostering a learning community. By understanding more about our unique online student population and the ways in which they create and identify communities, it is important to "identify the sources of support for connection in online doctoral programs, researchers and practitioners can design programs that support distance learners' satisfaction, persistence, and retention" (Berry, 2017 , p. 35). Many of our students work full-time, are actively engaged in their families and communities at home and began careers after receiving their bachelor's degrees years prior. With this level of involvement at home and at work, our doctoral students have different levels of support needs than traditional students (Cockrell \& Shelley, 2011). By providing services like student success coaches, writing center support, and career services, our students indicated that they received the help they need to navigate the new landscape of the doctoral journey. Bagaka et al. (2015) found that the quality of program support is a significant predictor of student success.

Perhaps one of the most surprising findings from this study, was the number of participant responses that highlighted the role of the faculty in promoting community. While many student comments emphasized peer collaboration, shared learning, the cohort model, and student support services, the most frequently occurring comment centered on faculty. Students indicated that the relationships they developed with their faculty advisor and other faculty engaged in the program who spent time emphasizing the development of scholars were key in their success and commitment to the program (Bagaka's et. al, 2015). Bagaka's et al. (2015) also highlighted the important role that faculty-student relationships play in the ongoing success of doctoral students. They found two items that were important to faculty student relationships including the accessibility of the faculty advisor and the willingness of faculty to spend time with the student. While their work specifically focuses on the role of formal faculty mentors or advisors, we believe that this kind of support from all faculty was important to our students' sense 
of support and community. Certainly, this relationship was strengthened through the interactions students had with faculty in live sessions and immersion experiences as well. In addition, students are assigned a dedicated faculty advisor to help guide them through their Problem of Practice dissertation beginning in the fourth trimester of the program. Faculty advisors teach the students in four distinct Problem of Practice courses and guide students through their ongoing dissertation process. In our case, the faculty, students, and program, all benefit from intentional interactions between our faculty and students. Formal and informal faculty mentorship is important in helping students develop confidence and competence in their role as a doctoral student (Hayes, 2005).

We believe the development of a community of learners and practice helps students in our program to persist at a higher rate and experience greater academic success than other online programs. Research suggests that over $40 \%$ of those who begin a residential doctoral program do not complete their degree, and the attrition rate for online doctoral programs is even higher at 60-70\% (Golde, 2005; Terrell, 2005; Terrell et al., 2012). As noted earlier, our current attrition rate of $17 \%$ has been minimized through our efforts to develop community. These outcomes are particularly important in ensuring successful program matriculation for our very diverse student population.

\section{CONCLUSION AND FUTURE DIRECTIONS}

The findings from this study suggest the EdD online program design has produced a myriad of positive outcomes in terms of community. Our program is committed to community building as a central value proposition. We have high expectations for all of our students and provide support for them throughout their journey towards degree attainment - both academic support and social/emotional support. Through purposeful programmatic structures focused around building community, students feel they are a part of our university community even though many reside thousands of miles from campus. As a result, students invest in their courses, their cohort, and their Problem of Practice dissertation early in the program. The cohort model and purposeful programmatic community building elements contribute to students' sense of belonging and purpose in the program. Our program is focused not only on high academic standards and rigor, but also the lives of our students and how they work together within our program to build a community of scholars with real hopes and dreams in their quest to influence their workplaces through new knowledge and skills. As Wenger et al. (2002) noted:

The most successful communities of practice thrive where the goals and needs of the organization intersect with the passions and aspirations of the participants. If the domain of a community fails to inspire it's members, the community will flounder...the intersection of personal meaning and strategic relevance is a potent source of energy and value. (p. 32)

The development and implementation of our program has not been without its own challenges. Our efforts to develop community and increase student persistence have evolved over the past three years. We have tried things that have worked and others that have not worked as well, so we continue to adjust. Finding the right balance for our students is the most challenging aspect of implementing new initiatives, primarily because our student population includes so many full-time working professionals who just do not have the time or energy to include many extra activities into their schedule. For instance, we have tried to offer webinars on a variety of topics outside students' class time as well as virtual immersion experiences (due to COVID-19) and these have not been terribly well received. In addition, we have found that as our program continues to grow in size, our ability to provide high quality program support has become more challenging. As an example, our writing center is always at full capacity and students must sign up far in advance in order to secure an appointment. This is a point of frustration for some of our students. In response, our writing center has created a number of web-based modules and resource guides to assist students while they wait on individual meetings with writing consultants. We have also invested in resources for students such as Turn-it-In and Grammarly. Additionally, as the program grows, we continue to consider how we can cultivate high quality student-faculty relationships with both faculty advisors and program faculty in general including maintaining smaller class sizes $(<20)$ and faculty advisor loads (<15). However, we are committed to continuous improvement which involves listening to our students, faculty, and staff and working together to design meaningful and effective experiences for all involved (Aggarwal et al., 2006, Dittmar \& McCraken, 2012). As program faculty and staff, we meet regularly to discuss and debrief what is working well and what is not. To assess program quality and student experiences, we collect multiple forms of data each trimester including course evaluations, faculty questionnaires, program-wide surveys, and interviews. We utilize this feedback and data as a driving force in our decision making about program improvement and modifications.

As the number of online doctoral programs continues to grow, it is imperative to consider how to design programs that promote sustainable and equitable outcomes for students. We argue that programs should carefully consider how they might implement programmatic structures to cultivate community and communities of practice. In this article, we have described several strategic practices we employ to build community in our online EdD program. It is our intent through describing these community building practices and associated student outcomes, that our experiences might serve as a useful guide to those working in other online doctoral programs. Ultimately, we take substantial strides to ensure our students are not only positioned for success in our program, but also feel appreciated, valued, and heard through the myriad of community building strategies that we utilize. Based on the evidence provided through this study, we are making great progress to foster community in an online doctoral program.

\section{REFERENCES}

\footnotetext{
Aggarwal, A. K., Adlakha, V., \& Mersha, T. (2006). Continuous improvement process in web-based education at a public university. E-Service Journal, 4(2), 3-26. https://doi:10.1353/esj.2006.0007.

Berry, S. (2017). Student support networks in online doctoral programs: Exploring nested communities. International Journal of Doctoral Studies, 12, 33-48. Retrieved from http://www.informingscience.org/Publications/3676

Bettinger, E., \& Loeb, S. (2017). Promises and pitfalls of online education (Evidence Speaks Reports Vol 2, \#15). Brookings. https://www.brookings. edu/wpcontent/uploads/2017/06/ccf_20170609_loeb_evidence_speaks1.pdf

Bista, K., \& Cox, D. W. (2014). Cohort-based doctoral programs: What we have learned over the last 18 years. International Journal of Doctoral Studies, 9(1), 1-20.
} 
Browne- Ferrigno, T. \& Maughan, B. D. (2016) Building and sustaining a learning cohort. In J. A. Perry (Ed.), The EdD and the Scholarly Practitioner, (pp. 45-63). Information Age Publishing

Creswell, J. W. (2002). Educational research: Planning, conducting, and evaluating quantitative and qualitative research. Merrill.

Carnegie Project on the Education Doctorate (CPED). (2010). Retrieved from http://www.cpedinitiative.org/design-concept-definitions

Cockrell, C. N., \& Shelley, K. (2011). The Relationship between Academic Support Systems and Intended Persistence in Doctoral Education. Journal of College Student Retention: Research, Theory \& Practice, 12(4), 469-484. https://doi.org/10.2190/CS.12.4.e

Curtin, N., Stewart, A. J., \& Ostrove, J. M. (2013). Fostering academic selfconcept: Advisor support and sense of belonging among international and domestic graduate students. American Educational Research Journal, 50(1), 108-137.

Cross, K. P. (1998). Why learning communities? Why now?. About campus, 3(3), 4-11.

Dittmar, E., \& McCracken, H. (2012). Promoting Continuous Quality Improvement in Online Teaching: The META Model. Journal of Asynchronous Learning Networks, 16(2), 163-175. http://dx.doi.org/10.24059/olj.v16i2.269

Eggens, L., van der Werf, M.P.C. \& Bosker, R.J. (2008). The influence of personal networks and social support on study attainment of students in university education. Higher Education, 55, 553-573. https://doi.org/10.1007/s10734-007-9074-4

Endo, J., \& Harpel, R. L. (1982). The effect of student-faculty interaction on students' educational outcomes. Research in Higher Education, 16(2), 115-138.

Gardner, S. K. (2008). Fitting the mold of graduate school: A qualitative study of socialization in doctoral education. Innovative Higher Education, 33(2), 125-138. https://doi.org/10.1007/s10755-008-9068-x

Gisemba Bagaka, J., Bransteter, I., Rispinto, S., \& Badillo, N. (2015). Exploring student success in a doctoral program: The power of mentorship and research engagement. International Journal of Doctoral Studies, 10, 323342. https://doi.org/10.28945/2291

Golde, C. M. (2005). The role of the department and discipline in doctoral student attrition: Lessons from four departments. The Journal of Higher Education, 76(6), 669-700.

Hayes, E. F. (2005). Approaches to mentoring: How to mentor and be mentored. Journal of the American Association of Nurse Practitioners, 17(11), 442.

Hill, M. S. (1995). Education leadership cohort models: Changing the talk to change the walk. Planning and Changing, 26(3/4), 179-189.

Ivankova, N. V., \& Stick, S. L. (2007). Students' persistence in a distributed doctoral program in educational leadership in higher education: A mixed methods study. Research in Higher Education, 48(1), 93.

Kerrigan, M. R., \& Hayes, K. M. (2016). EdD students' self-efficacy and interest in conducting research. International Journal of Doctoral Studies, 11, 147-162.

Lange, N. de, Pillay, G., \& Chikoko, V. (2011). Doctoral learning: A case for a cohort model of supervision and support. South African Journal of Education, 31(1), 15-30. https://doi.org/10.15700/saje.v31n1a413

Lave, J., \& Wenger, E. (2002). Legitimate peripheral participation in communities of practice. Supporting lifelong learning: Perspectives on learning, 1, 111.

Lovitts, B. E. (2001). Leaving the Ivory Tower: The causes and consequences of departure from doctoral study. Rowman \& Littlefield.

Lowery, K., Geesa, R., \& McConnell, K. (2018). Designing a peer-mentoring program for education doctorate (EdD) students. Higher Learning Research Communications, 8(1), 3-50. 10.18870/hlrc.v8i1.408

Maher, M. A. (2005). The evolving meaning and influence of cohort membership. Innovative Higher Education, 30(3), 195-211. https://doi.org/10.1007/s10755-005-6304-5

McMillan, D. W., \& Chavis, D. M. (1986). Sense of community: A definition and theory. Journal of Community Psychology, 14(1), 6-23. https://doi.org/10.1002/1520-6629(198601)14:1<6::AIDJCOP2290140103>3.0.CO;2-I

Merriam, S. B. (2008). Adult learning theory for the twenty-first century. New Directions for Adult and Continuing Education, 2008(119), 93-98. https://doi.org/10.1002/ace.309
Moore, M. G. (1993). Theory of transactional distance. Theoretical Principles of Distance Education, 1, 22-38.

Norris, C. J., \& Barnett, B. (1994). Cultivating a new leadership paradigm: From cohorts to communities. https://eric.ed.gov/?id=ED387877

Reynolds, K. C., \& Hebert, F. T. (1998). Learning achievements of students in cohort groups. The Journal of Continuing Higher Education, 46(3), 34-42. https://doi.org/10.1080/07377366.1998.10400354

Rockinson-Szapkiw, A. J., Spaulding, L. S., \& Bade, B. (2014). Completion of educational doctorates: How universities can foster persistence. International Journal of Doctoral Studies, 9, 293-308.

Rourke, L., Anderson, T., Garrison, D. R., \& Archer, W. (1999). Assessing social presence in asynchronous text-based computer conferencing. The Journal of Distance Education / Revue de l'ducation Distance, 14(2), 5071.

Rovai, A. P. (2003). In search of higher persistence rates in distance education online programs. The Internet and Higher Education, 6(1), 1-16.

Rovai, A. P., \& Wighting, M. J. (2005). Feelings of alienation and community among higher education students in a virtual classroom. The Internet and Higher Education, 8(2), 97-110. https://doi.org/10.1016/j.ineduc.2005.03.001

Schaffhauser, D. (2020, March 25). Enrollment in Online Programs Flattening for Now. Campus Technology. https://campustechnology.com/articles/2020/03/25/enrollment-in-onlineprograms-flattening-out-for-now.aspx

Stake, R. E. (2006). Multiple case study analysis. Guilford Press.

Strauss, A., \& Corbin, J. M. (1990). Basics of qualitative research: Grounded theory procedures and techniques. Sage.

Swan, K., Shea, P., Fredericksen, E., Pickett, A., Pelz, W., \& Maher, G. (2000) Building knowledge building communities: Consistency, contact and communication in the virtual classroom. Journal of Educational Computing Research, 23(4), 359-383. https://doi.org/10.2190/W4G6HY52-57P1-PPNE

Terrell, S. R. (2005). A longitudinal investigation of the effect of information perception and focus on attrition in online learning environments. The Internet and Higher Education, 8(3), 213-219.

Terrell, S. R., Snyder, M. M., Dringus, L. P. \& Maddrey, E. (2012). A grounded theory of connectivity and persistence in a limited residency doctoral program. Qualitative Report, 17(62), 1-14.

Tinto V. (2010) From theory to action: Exploring the institutional conditions for student retention. In J. Smart (Ed.), Higher Education: Handbook of Theory and Research, (pp. 51-89). Springer. https://doi.org/10.1007/97890-481-8598-6 2

Tinto, V. (2003). Learning better together: The impact of learning communities on student success. Higher Education Monograph Series, 1(8), 1-8.

Tu, C. H., \& Corry, M. (2003). Building active online interaction via a collaborative learning community. Computers in the Schools, 20(3), 5159.

Tuñón, J., \& Ramirez, L. (2010). ABD or EdD? A model of library training for distance doctoral students. Journal of Library Administration, 50(7-8), 989-996.

Wenger, E. (1998). Communities of practice: Learning as a social system. The Systems Thinker, 9(5), 1-5.

Wenger, E., McDermott, R. A., \& Snyder, W. (2002). Cultivating communities of practice: A guide to managing knowledge. Harvard Business School Press.

Wentzel, K. R. (1999). Social-motivational processes and interpersonal relationships: Implications for understanding motivation at school. Journal of Educational Psychology, 91(1), 76. 